\title{
DESAFIOS E PERSPECTIVAS \\ DO CURSO DE ARQUIVOLOGIA DA \\ UNIVERSIDADE ESTADUAL DE LONDRINA
}

\author{
Terezinha Elisabeth da Silva \\ Daniella Debertolis \\ Jordano Wanderley Hernandez
}

\begin{abstract}
Resumo
Impressões sobre o curso de Arquivologia da Universidade Estadual de Londrina, utilizandose dados quantitativos e qualitativos coletados em questionário e observações. Relata breve histórico do curso, criado em 1998 e surgido de parceria entre os Departamentos de Ciências da Informação e de História. Expõe o perfil da turma do atual $1^{\circ}$ ano, incluindo dados pessoais, conhecimento prévio de conceitos da área, razões de escolha, além de expectativas em relação ao curso e à profissão. Relata as percepções dos corpos docente e discente sobre a implantação e andamento do curso. Com postura crítica, os acadêmicos apresentam também soluções e sugestões, se envolvem nas questões relativas ao curso.
\end{abstract}

\section{Palavras chave}

Arquivologia - Ensino

\section{INTRODUÇÃO}

O presente trabalho, escrito por alunos do atual $1^{\circ}$ ano de Arquivologia e por professora do Departamento de Ciências da
Informação da Universidade Estadual de Londrina - UEL, tem a finalidade de relatar as impressões sobre o referido Curso, na perspectiva dos discentes e da docente envolvidos. Para tanto, foram utilizados dados quantitativos, obtidos de questionário elaborado pela professora e respondido por alunos do $1^{\circ}$ ano, e dados qualitativos, 
coletados a partir das questões abertas constantes do mesmo questionário, de observações cotidianas e de relatos dos alunos em reunião que será oportunamente mencionada.

\section{CURSO DE ARQUIVOLOGIA DA UEL}

Criado em 1998, o Curso de Graduação em Arquivologia da UEL é o quinto do Brasil. Surgido a partir de parceria entre os Departamentos de Ciências da Informação e de História, tem, dentre outros, o objetivo de formar recursos humanos para a prática arquivística, visando o mercado regional, uma vez "que os cursos implantados e em funcionamento não atendem à demanda quantitativa de instituições públicas e privadas brasileiras." (MULLER, 1997, p.47)

Anteriormente à implantação foi realizada pesquisa de mercado e de clientela, na tentativa de verificar a viabilidade do Curso. Foram enviados questionários à administração pública e privada de vários setores do Estado, e entrevistados 983 estudantes de três escolas de segundo grau da cidade de Londrina. É relevante destacar alguns dados da pesquisa. Embora 46\% das instituições contactadas tenham assumido a grande importância do arquivo para a organização, apenas $12 \%$ das que empregavam funcionários no setor, possuíam arquivistas. Quanto aos alunos de segundo grau pesquisados, apenas 103 afirmaram que não optariam pelo Curso de Arquivologia, embora a maioria dos entrevistados não tivesse noção da profissão e do mercado de trabalho. (MULLER, 1997)
Com proposta curricular que tenciona favorecer e manter a integração entre teoria e prática, de modo a fortalecer os vínculos necessários entre as técnicas arquivísticas e a formação humanística, o Curso de Arquivologia da UEL está hoje em seu segundo ano de funcionamento. Embora seja novo na UEL e na cidade de Londrina e seja área de formação recente na Universidade brasileira, pode-se perceber a aceitação pela comunidade estudantil préuniversitária, demonstrada pela crescente demanda no concurso vestibular: 1,55 e 5,10 candidatos/vaga em janeiro de 98 e 99, respectivamente; 1,9 e 3,75 candidatos/vaga em julho de 98 e julho de 99 , respectivamente.

\section{1 ANO DE ARQUIVOLOGIA - SEGUNDA TURMA}

No início do período letivo de 1999, precedendo a disciplina "Fundamentos da Ciência da Informação e da Arquivologia", ministrada para o $1^{\circ}$ ano, foi realizada pesquisa para conhecimento da turma. Na oportunidade estavam presentes $33(82,5 \%)$ dos 40 alunos matriculados, que responderam a questões que visavam fornecer o perfil da turma, incluindo dados pessoais, conhecimento prévio de conceitos da área, razões de escolha, além de expectativas em relação ao curso.

\subsection{Perfil da Turma}

Do total de respondentes, $72,7 \%$ são do sexo feminino e $27,3 \%$ do sexo masculino. As idades variam entre 17 e 52 anos, sendo que a faixa etária predominante é entre 21-30 anos, correspondendo a 39,3\%. Os alunos entre 17-20 anos, somam $24,3 \%$, o que também se verifica na faixa etária entre $31-40$ anos (24,3\%). 
Dentre os alunos, 69,7\% já trabalham. A maioria reside em Londrina (84,8\%) e os outros $(15,2 \%)$ em cidades próximas.

Verificou-se que $12,1 \%$ têm outro curso superior; $12,1 \%$ iniciaram algum curso superior sem conclusão; mas a maioria $(75,8 \%)$ encontra-se em sua primeira graduação.

\subsection{Motivos de escolha do Curso}

No tocante às questões relativas à escolha do Curso, constatamos várias semelhanças entre a nossa realidade e as observações apresentadas pela professora Heloísa Bellotto no artigo "A imagem do arquivista na sociedade e o ensino da Arquivologia" (BELLOTTO, 1996), como pode ser verificado a seguir.

A baixa concorrência do Curso no vestibular é o principal motivo de escolha, pois os futuros alunos "notam tratar-se de um curso universitário menos procurado (...) Há, portanto, maior possibilidade de ingresso." (BELLOTTO, 1996, p.13)

O segundo motivo refere-se aos benefícios que podem advir de um campo de trabalho ainda inexplorado e em expansão, uma vez que, até áreas mais concorridas no vestibular e melhor reconhecidas pela sociedade enfrentam, em decorrência da crise econômica, problemas para colocação dos profissionais no mercado de trabalho.

Em terceiro lugar vêm as possibilidades que um Curso como a Arquivologia, abrangente na percepção do ingressante, oferece em termos de "crescimento cultural" e de conhecimento. Assim, para alguns, o Curso é visto como uma forma de "enriquecimento cultural", ou como a possibilidade de apreensão/ampliação de conhecimentos bastante gerais através das disci- plinas do currículo.

Existem também os ingressantes que relacionam o Curso com a pesquisa histórica e a informática. Isto significa que, ou "aliam o trabalho arquivístico à informática porque chegam a compreender que a matéria-prima profissional é, igualmente a informação" ou "imaginam, sobretudo os que têm grande gosto pela história que (...) irão desenvolver exclusivamente atividades de pesquisa histórica." (BELLOTTO, 1996, p.13)

Alguns alunos dizem ter optado pelo Curso por trabalharem, direta ou indiretamente, com arquivos. Finalmente, poucos assumiram que a opção se deve a fatos circunstanciais como reportagens em jornais, revistas e televisão, participação em congressos e conferências.

\subsection{Formas de conhecimento e expec- tativas em relação ao Curso}

A maioria dos alunos obteve conhecimento do Curso através de amigos, parentes e alunos da primeira turma (39,5\%). O "Manual do Candidato" do Concurso Vestibular da UEL atraiu 18,4\% dos alunos, seguido pelo "Guia do Estudante" da Editora Abril e pela imprensa local (10,5\% cada). O "Boletim Informativo da UEL" e os cursos pré-vestibulares da cidade foram responsáveis por $7,9 \%$ cada. Os $5,3 \%$ restantes obtiveram conhecimento através da pesquisa, citada anteriormente, realizada para implantação do Curso.

Há, no entanto, casos curiosos como o que relata um aluno:

"Ouvi comentários em uma fila de banco, duas moças dizendo que o Curso era novo e promissor." (aluno) 
Em relação às expectativas, a maioria dos alunos pretende com o Curso, conseguir "bons empregos", sendo "bons profissionais", aplicando os conhecimentos adquiridos em sua área de trabalho.

As expectativas relacionam-se diretamente aos motivos de escolha do Curso. Aqueles alunos que foram "levados" a optar pela Arquivologia, principalmente pela baixa concorrência, não têm claras as expectativas, como pode-se verificar:

"Espero que seja um Curso tão bom quanto falam, e se for, vou levá-lo até o fim, pois quero ser formado em alguma coisa um dia." (aluno 1) (grifo nosso)

"Que seja um bom Curso e que eu goste e consiga acompanhálo até o fim. E até, quem sabe, seguir a profissão." (aluno 2) (grifo nosso)

Por outro lado, há alunos que demonstram ter feito a escolha conscientemente $\mathrm{e}$ por isto vislumbram mais claramente as expectativas. Neste caso, elas são:

"As melhores possíveis. Tornarme um profissional de futuro, já que este é um dos Cursos do futuro." (aluno 3 )

"De satisfação profissional, inteiramente ligada à satisfação pessoal (fazer o que se gosta, trabalhar com o escolhido). Realização como cidadão, capaz e com anseios." (aluno 4)

\section{PERCEPÇÕES SOBRE A IM- PLANTAÇÃO E ANDAMENTO DO CURSO}

Visando aprimoramento e integração, a Coordenação do Curso reuniu, em meados de 1999, os corpos discente e docente no evento denominado "Percepções sobre a implantação e andamento do Curso". Após palestra do professor José César dos Reis, alunos e professores foram divididos em grupos de forma a trabalhar a questão proposta no título do evento, para verificação de problemas e avanços ocorridos desde a implantação do Curso.

Naquela oportunidade, pôde-se perceber alguns pontos que perpassaram as discussões de todos os grupos. Os alunos demonstram grande ansiedade em relação ao mercado de trabalho e ao próprio desenvolvimento do Curso, uma vez que, por ser novo, "muito existe a ser aprimorado". Ainda que esta ansiedade estivesse e esteja presente cotidianamente, o corpo discente tem noção do amplo mercado de trabalho (potencial) que o aguarda após a conclusão.

As maiores dificuldades apontadas referem-se ao fato de o Curso e a profissão de arquivista serem pouco divulgados, o que é acentuado pela inexistência de referenciais (instituições arquivísticas) na cidade de Londrina. A Coordenação do Curso tem suprido esta falta organizando visitas dos alunos a instituições de outras cidades.

Outro fator preocupante para a maioria dos alunos diz respeito à especialização do corpo docente, uma vez que, na maioria, são professores de áreas afins que suprem a falta de docentes especializados em Arquivologia, problema que também é enfrentado por cursos de outras universi- 
dades. Por isto os alunos vêem com grandes expectativas o retorno de duas professoras que se encontravam em capacitação na Universidade de São Paulo.

O acervo incipiente na área de Arquivologia é outra preocupação do corpo discente. Em relação a isto, muito embora a direção da Biblioteca Central da UEL se mostre sensível e tenha buscado ampliar o acervo, sabe-se que o mercado editorial brasileiro dispõe de poucos títulos em catálogo.

Os alunos do $1^{\circ}$ ano ainda têm dificuldade de entender o relacionamento entre as disciplinas do currículo, o que, em parte, foi superado pelo $2^{\circ}$ ano, uma vez que visitas a várias instituições arquivísticas de São Paulo, realizadas em 1998, permitiram o entendimento da importância do arquivista no gerenciamento documental e as bases curriculares necessárias.

Muitos discentes, mesmo do $2^{\circ}$ ano, ainda não percebem a importância das disciplinas teóricas e admitem ser fundamental conhecer na prática as necessidades de organização documental. De fato, conforme Jardim (1994), "muitos alunos tendem a considerar as questões teóricoconceituais como uma instância pouco relevante em sua formação."

Os alunos, na sua maioria, entendem que o reconhecimento e a valorização profissional dependem muito do seu desempenho futuro no mercado de trabalho, o que demonstra a responsabilidade da Universidade na formação dos profissionais, principalmente destes profissionais que serão os egressos das primeiras turmas.

Sabem que a Arquivologia é uma área com grande potencial, amplo mercado a ser explorado, mas reconhecem que a valorização profissional é decorrente do traba-
Iho realizado com responsabilidade e dedicação.

Muito embora existam ansiedades e inseguranças, os alunos têm boas perspectivas em relação ao futuro do Curso e de seu próprio futuro profissional. Neste sentido, percebem que a terceirização dos serviços arquivísticos é uma das tendências atuais e futuras e que, paradoxalmente, o mercado é promissor justamente pela inexistência de profissionais capacitados na área.

Finalmente, e como forma de contribuir socialmente, os futuros profissionais esperam não perder de vista a luta em favor da disponibilização de informações para a construção da cidadania. Entendem, porém, que é necessário mudar antes suas concepções para depois tentar "mudar o mundo".

\section{CONCLUSÃO}

No Curso de Arquivologia da UEL, nota-se grande heterogeneidade em relação às idades dos alunos, às razões de escolha do Curso e às expectativas dos discentes, além do quê, há predominância do sexo feminino. Todos estes aspectos ratificam o quadro existente nos cursos da área de Ciência da Informação do país.

Percebe-se também que a falta de reconhecimento profissional e de conhecimento das funções do arquivista seriam as principais responsáveis por escolhas não conscientes do Curso, o que não difere da condição de outras graduações em Arquivologia do Brasil.

Apesar de apontar dificuldades, os acadêmicos apresentam soluções, se envolvem efetivamente nas questões porque crêem no aprimoramento do Curso e assim 
investem em seu próprio futuro profissional. Sabem que melhor divulgação e o reconhecimento social da profissão advêm do desenvolvimento do Curso do qual fazem parte e pelo qual se sentem responsáveis.

Ainda que seja resultado de impressões, observações e de pesquisa não realizada para este fim específico, acreditamos na importância deste trabalho para o aprimoramento do Curso da UEL e, porque não dizer, dos demais Cursos de Arquivologia no Brasil, uma vez que os resultados apontam questões que podem ser universalizadas. Assim, quando apresentamos nossa realidade, contribuímos para o desvelamento de aspectos que devem ser pensados e trabalhados por outras graduações em Arquivologia.

\section{QUESTIONÁRIO}

No questionário respondido pelos alunos no primeiro dia de aula, foram solicitadas as seguintes informações:

1. Sexo

2. Idade

3. Se trabalha, local de trabalho:

4. Cidade de residência

5. A Arquivologia é sua primeira graduação? Caso não seja, já iniciou/ concluiu outro curso superior? Qual?

6. Motivos que levaram à escolha do Curso?

7. De que forma soube da existência do Curso?

8. Que expectativas tem em relação ao Curso?

\section{REFERÊNCIAS}

BELLOTTO, Heloísa Liberalli. A imagem do arquivista na sociedade e o ensino da Arquivologia. Arquivo \& História, n.2, p. 716, 1996.

JARDIM, José Maria. A universidade e o ensino da Arquivologia no Brasil. In: CONGRESSO BRASILEIRO DE ARQUIVOLOGIA, 10., 1994, São Paulo. Anais. São Paulo: AAB - Núcleo Regional de São Paulo, 1998 [CD-ROM].

MULLER, Mary Stella (Coord.) Curso de Arquivologia da UEL: consolidação de uma proposta de parceria. Informação \& Informação, v.2, n.1, p. 45-66, jan./jun. 1997. 


\section{Terezinha Elisabeth da Silva}

Professora do Departamento de Ciências da Informação - Centro de Educação, Comunicação e Artes - Universidade Estadual de Londrina

Londrina - PR - Brasil - telis@uel.br

\section{Daniella Debertolis}

Aluna do Curso de Arquivologia da Universidade Estadual de Londrina

\section{Jordano Wanderley Hernandez}

Aluno do Curso de Arquivologia da Universidade Estadual de Londrina

\section{Title}

Challenges and Perspectives of the Archival Studies Course of the State University of Londrina

\section{Abstract}

Impressions on the Archival Studies Course of the State University of Londrina, making use of quantitative as well as qualitative data, gathered by means of a questionnaire and observations. It presents a brief history of the course, which started in 1998 as a result of a partnership between the Information Sciences and History Departments. It presents the profile of the current first year group including personal data, previous knowledge of concepts of the area, reasons or choosing the course as well as the profession. It relates the teachers' and students' opinions on the implementation and directions of the Course. The students present solutions and suggestions and take part in the issues which are related to the course.

\section{Keywords}

Archival studies

\section{Titulo}

Desafios y perspectivas del curso de Archivologia de la Univesidad Estatal de Londrina

\section{Resumen}

Impresiones sobre el curso de Archivología de la Universidad Estatal de Londrina, utilizando datos cuantitativos y cualitativos obtenidos por cuestionario y observaciones. Relata breve histórico del curso, creado en 1998 y que surgió de la parceria entre los Departamentos de Ciencias de la Información y de História. Expone el perfil del grupo del actual $1^{\circ}$ año, incluyendo datos personales, conocimiento previo de conceptos del área, razones de elección, más allá expectativas en relación al curso y a la profesión. Relata las percepciones de los docentes y discentes sobre la implantación y la marcha del curso. Con actitud crítica, los académicos presentan también soluciones y sugerencias, se comprometen con las cuestiones relativas al curso.

Palabras-Clave

Archivología - Enseñanza

Artigo recebido em: 04/09/2000 